\title{
Market Pricing of Exotic Structured Products: The Case of Multi-Asset Barrier Reverse Convertibles in Switzerland
}

\author{
Martin Wallmeier, Martin Diethelm*
}

This Version: August 2008

\begin{abstract}
The market for structured financial products in Switzerland ranks among the largest in the world. A unique characteristic of the Swiss market is that its most successful products are reverse convertibles on multiple assets with conditional capital protection (multiple barrier reverse convertibles, MBRC). In other countries, an active market only exists for simpler types of reverse convertibles. The valuation of MBRCs is not straightforward, and pricing tools are not yet publicly available. Thus, transparency with respect to fair values might be poor, and it is not obvious that the competition between issuers is strong enough to ensure "fair" pricing. We provide the first empirical study on market pricing of MBRCs based on a comprehensive database of 468 certificates outstanding in April 2007. Using a numerical, tree-based valuation method, we obtain an average overpricing of at least $3.4 \%$. This premium on the entire product corresponds to a price discount of $29 \%$ on the embedded short put. The overpricing is positively related to the coupon level, indicating that investors tend to overweight the sure coupon and underestimate the risk involved. This behavioral bias appears to be important in explaining the success of the product.
\end{abstract}

JEL classification: G13; G15; G14

Keywords: Structured Products, Reverse Convertibles, Multi-Asset Options, Barrier Options, Financial Engineering.

${ }^{*}$ Prof. Dr. Martin Wallmeier (corresponding author), Martin Diethelm, Department of Finance and Accounting, University of Fribourg / Switzerland, Bd. de Pérolles 90, CH-1700 Fribourg, martin.wallmeier@unifr.ch 


\section{Introduction}

The Swiss market for structured financial products ranks among the largest in the world and is still growing rapidly. ${ }^{1}$ Structured products consist of two or more different components, one of which must be a derivative (see Stoimenov and Wilkens (2005)). They are issued by banks and may be addressed to private or institutional investors. The products can be traded on an organized exchange or sold directly by their issuing bank, who will quote bid and ask prices. A unique characteristic of the Swiss market is that structured products with "exotic" options are extremely prominent. In particular, barrier reverse convertibles represent more than one third of the market (in terms of the total number of products). The majority of these contain multi-asset options, and are called multiple barrier reverse convertibles (MBRC). ${ }^{2}$ In other countries, an active market only exists for simpler types of reverse convertibles. Thus, the Swiss market offers an exceptional opportunity to study the evolution of financial design, investor behavior and the pricing of complex financial instruments.

The buyer of an MBRC is entitled to receive a fixed coupon payment on its face value, just like the buyer of a straight bond. In contrast to a bondholder, however, he may receive assets instead of cash repayment of the face value at maturity. The issuer of the MBRC has the right to deliver the underlying asset with the worst performance, provided that at least one of the assets has crossed a downside barrier during the lifetime of the contract. In Switzerland, most MBRCs have an initial time to maturity of one year and are based on three underlying stocks.

Although market pricing of some classes of structured products is well documented in the literature ${ }^{3}$ MBRCs appear to be particularly interesting for at least three reasons. First, in one of the major markets, the product is more prominent and practically relevant than any other structured product with 'exotic' elements. Second, due to the complexity of the instrument, its valuation is not straightforward. Since no suitable pricing tools are publicly available, transparency with respect to fair values and value determinants is supposed to be poor. For this reason, it is questionable whether the competition between issuers is strong enough to ensure fair pricing. Third, MBRC are constructed such that two attractive features stand out, namely the high coupon payment (of typically about 10\%) and the conditional capital protection (in case none of the barriers is broken). If investors with bounded rationality pay too much attention to these features, they might show an exaggerated willingness-to-pay. As a result, overpricing might be particularly pronounced. Its magnitude is important for investors as well as regulators of financial markets.

To the best of our knowledge, this is the first empirical study of MBRC pricing. Our study is based on a unique and comprehensive database of $468 \mathrm{MBRC}$ in the primary Swiss market. We propose a fast and accurate numerical valuation method based on the tree model of Chen et al. (2002) which is a significant improvement over the commonly used Monte Carlo simulation. A

1 End of June 2008, it contained more than 8,000 outstanding instruments.

2 These have been heavily promoted by some issuers. In 2007, more than 700 full-page advertisements appeared in the most respected Swiss newspaper "Neue Zürcher Zeitung" and the business paper "Finanz und Wirtschaft".

3 See, e.g., Hernandez et al. (2007), Benet et al. (2006), and Stoimenov and Wilkens (2005). 
further main contribution is to go beyond a descriptive analysis of price differences by examining the role of market frictions and behavioral biases as determinants of overpricing.

We obtain an average overpricing in the range of $3.4 \%$ to $6 \%$ for 468 certificates outstanding in April 2007. If this premium is attributed only to the short put option embedded in the product, it corresponds to an average price discount of at least $29 \%$. The product overpricing turns out to be positively related to the coupon level, suggesting that investors tend to overweight the value of the sure coupon and downplay the risk involved. This behavioral bias appears to be important in explaining the success of the product.

The remainder of the paper is structured as follows: in Section 2, we review the literature on pricing reverse convertibles. In Section 3, we characterize the MBRC and present our valuation model. Sections 4 to 6 contain the hypotheses, a description of the database, and our empirical results. We conclude with a brief summary of our findings.

\section{Literature review}

Most empirical studies on structured financial products focus on European markets, especially Switzerland, Germany and the Netherlands. All take the approach of comparing prices in the primary or secondary market to theoretical fair values. The fair values of embedded options are typically estimated based on the implied volatilities of similar publicly traded options.

Analyzing 199 reverse convertibles and 76 discount certificates on Swiss blue chips outstanding in August 1999, Burth et al. (2001) find a significant average overpricing of $1.91 \%$ in the primary market. Prices in the secondary market are also above theoretical values, as Wilkens et al. (2003) show for a sample of 169 reverse convertibles and 737 discount certificates over 22 trading days in November 2001. On average, the premium is $3.04 \%$ for reverse convertibles and $4.20 \%$ for discount certificates. These authors also find support for the life cycle hypothesis, which states that the premium is highest at issuance and declines as selling orders (among investors) become more important than buying orders. This pattern had already been detected in earlier studies, such as that of Schenk and Wasserfallen (1996) concerning capital protected notes in Switzerland.

Three studies on the pricing differences between products find a positive relationship between complexity and overpricing: Grünbichler and Wohlwend (2005) for Switzerland, Stoimenov and Wilkens (2005) for Germany and Hernandez et al. (2007) for an international sample. Stoimenov and Wilkens (2005) and Hernandez et al. (2007) report average premiums of $4.77 \%$ and $5.40 \%$ for barrier products, for instance, while simpler products trade at a premium of about $3 \%$. In contrast to these results, Szymanowska et al. (2007) find an average overpricing of more than $5 \%$ for 32 standard reverse convertibles listed on the Amsterdam Stock Exchange-but the average premium was negative for 43 barrier reverse convertibles (undervaluation of $0.63 \%$ ). They suspect that investors generally underestimate the value of the put option sold. This misjudgment is presumed to be less severe for barrier options, because they are less valuable than vanilla options with the same characteristics otherwise.

In the US market, Benet et al. (2006) examine the pricing of 31 "Reverse-Exchangeable Securities (RES)" outstanding in July 2003. They express the premium in terms of a coupon spread, 
indicating how much the coupon would have to be increased to obtain a fair value equal to the issuing price. The coupon spread estimates are significant, ranging from 4 to 6 percentage points. To explain this overvaluation, the authors turn to the concept of credit risk. They argue that holders of reverse convertibles are less exposed to the issuer's credit risk than bondholders, because any default on the part of the issuing bank will typically occur during a market depression when the value of the underlying asset and the contractual repayment will tend to be low. However, this explanation seems incompatible with the triple A rating of the issuing bank (ABN Amro). The corresponding credit spread was too low to have a significant influence on the fair values of the reverse convertibles under study.

To summarize, most estimates place the level of overpricing between $2 \%$ and $6 \%$ for simple reverse convertibles at issuance. Results for barrier reverse convertibles are mixed, however. Three studies report an overpricing of about $5 \%$, while one study finds an underpricing. To our knowledge, no studies focusing on MBRC pricing have yet been published.

A different stream of literature is devoted to the question why and under what conditions financial innovations are successful. Branger and Breuer (2008) show that CRRA investors do not considerably benefit from an investment in typical structured products. Shefrin and Statman (1993) analyze the design of innovative products from the perspective of behavioral finance theory, particularly the prospect theory of Kahneman/Tversky $(1979,1992)$. In line with this approach, Breuer and Perst (2007) assess the attractiveness of discount certificates and reverse convertibles to agents using cumulative prospect theory. As it turns out, in this setting agents are not interested in any of these instruments, because they tend to strongly weight the small probability of a repayment below the instrument's nominal value. Reverse convertibles, however, might be chosen by investors with bounded rationality, who put too much weight on the sure coupon payment (see the concept of mental accounting by Thaler (1985)). Grünbichler and Wohlwend (2005) express this view (p. 373): „Given the fact that capital-market interest rates were very low, it can be assumed that a number of investors allowed themselves to be enticed by the visually attractive coupon payments of structured products with coupons, but failed to make the correct appraisal of the risks inherent in such products." (see also Szymanowska et al. (2007)). In a theoretical analysis, Hens and Rieger (2008) confirm that mis-estimation is needed to explain the demand for many popular instruments. ${ }^{4}$

\section{$3 \quad$ Valuation of multiple barrier reverse convertibles}

\subsection{Payoff profile}

The holder of an MBRC receives a fixed coupon payment regardless of the prices of the underlying assets. Repayment at maturity is uncertain. It corresponds to the nominal value, if

- none of the prices of the underlying assets has been equal to or lower than its respective barrier during the time to maturity, or

\footnotetext{
4 This result could also explain, why parameters of prospect theory capturing individual risk preferences do not seem to be compatible with the same individuals' willingness to pay for investment products. This incompatibility has been convincingly documented by Erner et al. (2008).
} 


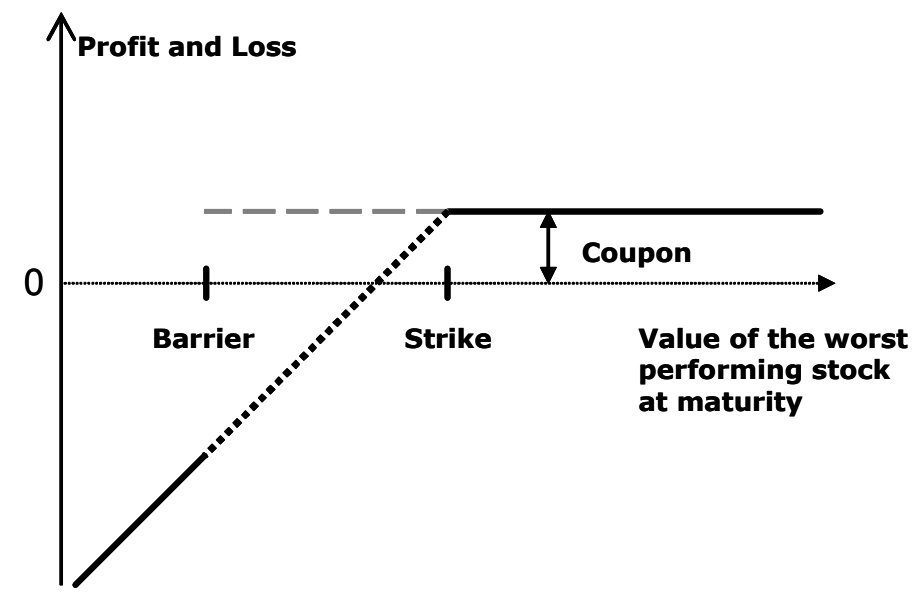

Figure 1: Profit and loss diagram of multi barrier reverse convertibles; dotted line: relevant if barrier has been triggered; broken line: relevant if barrier has not been triggered

- at maturity all asset prices are above their initial values.

Otherwise, at maturity the holder receives a predetermined amount of the underlying asset with the highest relative price reduction during the lifetime of the contract. The number of stocks is set such that their total market value is equal to the nominal contract value in the case of zero return. Thus, the investor's nominal capital is protected as long as none of the barriers is hit (see broken line in Figure 1), even if the stock prices are below strike at maturity. As soon as one barrier is triggered, however, the MBRC turns into a regular reverse convertible on multiple underlying assets (see the unbroken and dotted lines in Figure 1).

\subsection{Multinomial tree method}

The objective of this section is to value multi-asset barrier options under the assumptions of perfect financial markets and a multivariate geometric Brownian motion of stock prices with known expected returns, volatilities and pairwise correlations. In this setting, a perfect replication strategy exists so that the Martingale valuation approach can be applied (see Musiela and Rutkowski (2005), p. 298ff.). While analytical formulas for vanilla multi-asset options exist (Stulz (1982), Johnson (1987)), numerical methods are required when barriers are embedded. Among the commonly applied numerical procedures, Monte Carlo simulation has the desirable property that the number of computations rises only linearly with the number of underlying assets. However, as convergence is typically slow when barriers are considered (see Boyle and Lau (1994)), we use a tree method instead.

By assuming that the price of each underlying asset follows a binomial process, Boyle et al. (1989) extended the binomial model of Cox et al. (1979) and Rendleman and Bartter (1978) to multi-asset options. The result is a multi-dimensional binomial tree calibrated to match the moments of the multivariate log-normal distribution of stock returns. One weakness of the model is that its financial market is incomplete. More importantly, however, the number of nodes in the tree grows exponentially with the number of underlying assets. For $n$ assets and 
$s$ time steps, there are $(s+1)^{n}$ end nodes-more than one million for the rather spare choice $s=100, n=3$. Since barrier options require a large number of time steps to model correctly, this approach cannot be applied directly in our setting.

Chen et al. (2002) propose a multinomial tree with two or more branches for each asset, where not all combinations of asset movements are allowed. Each node represents a combination of values of the underlying assets (see similarly Rathgeber (2005)). The financial market in this model is complete, and the resulting multi-dimensional tree is partly recombining. The number of unique end nodes is given by $(s+n) ! / s ! / n$ !, which for small $n$ means a significant improvement over the Boyle et al. (1989) approach (176,851 nodes for $s=100, n=3)$. The method of Chen et al. (2002) can be extended to the valuation of barrier options by recalculating the value of nodes where the barrier is violated (see the basic insight of Cox and Rubinstein (1985)). We adopt this method for valuing triple barrier reverse convertibles (TBRC). The remainder of this section presents the model in more detail and illustrates its convergence behavior.

In the Chen et al. (2002) model, the stock returns are derived from a basic process with the following properties. Let $t$ denote the current point in time. We assume that four states of nature $\left(n=1, \ldots, 4\right.$ with probabilities $\left.\mathbf{p}=\left(p_{1}, p_{2}, p_{3}, p_{4}\right)^{\prime}\right)$ are possible after a time step of length $\Delta t .^{5}$ We define three processes $(k=1,2,3)$, each of which may produce a different result $\left(z_{n}^{k}\right)$ in each state of nature $n$. Defining $\mathbf{z}^{k}=\left(z_{1}^{k}, z_{2}^{k}, z_{3}^{k}, z_{4}^{k}\right)^{\prime}$, all possible outcomes can be contained in the $4 \times 3$-matrix $\mathbf{Z}=\left(\mathbf{z}^{1}, \mathbf{z}^{2}, \mathbf{z}^{3}\right)$. Each basic process produces one column, and each possible state of nature produces a row. The matrix elements $z_{n}^{k}$ and probabilities $p_{n}$ are chosen such that the expected value of each process is 0 (Equation 1), their variances are equal to 1 (Equation 2), and the variables are uncorrelated (Equation 3):

$$
\begin{aligned}
\left(\mathbf{z}^{k}\right)^{\prime} \mathbf{p}=0 \quad \forall k=1,2,3 \\
\left(\mathbf{z}^{k} \circ \mathbf{z}^{k}\right)^{\prime} \mathbf{p}=1 \quad \forall k=1,2,3 \\
\left(\mathbf{z}^{k} \circ \mathbf{z}^{l}\right)^{\prime} \mathbf{p}=0 \quad \forall k \neq l
\end{aligned}
$$

where $\circ$ is the operator for elementwise multiplication. This system of Equations (1)-(3) is under-determined, since there are 16 parameters and only 10 constraints (including $\sum p_{i}=1$ ). If we set $p_{n}=1 / 4 \forall n$, the 12 elements of $\mathbf{Z}$ remain to be chosen in accordance with the nine Equations (1)-(3).

From the set of all possible models, we consider two specifications:

$$
\mathbf{Z}=\mathbf{Z}^{(1)}=\left(\begin{array}{ccc}
\sqrt{3} & 0 & 0 \\
-\sqrt{3} / 3 & 2 \cdot \sqrt{2 / 3} & 0 \\
-\sqrt{3} / 3 & -\sqrt{2 / 3} & \sqrt{2} \\
-\sqrt{3} / 3 & -\sqrt{2 / 3} & -\sqrt{2}
\end{array}\right) ; \quad \mathbf{Z}=\mathbf{Z}^{(2)}=\left(\begin{array}{ccc}
\sqrt{2} & 0 & 1 \\
-\sqrt{2} & 0 & 1 \\
0 & -\sqrt{2} & -1 \\
0 & \sqrt{2} & -1
\end{array}\right)
$$

To transform the uncorrelated basic processes to correlated stock returns, we use the Cholesky decomposition $\boldsymbol{\Omega}=\mathbf{L} \mathbf{L}^{\prime}$ of the variance-covariance matrix $\boldsymbol{\Omega}$ of stock returns. Based on the

\footnotetext{
5 Here we describe the model in terms of the TBRC. However, it can easily be extended to the case of $K$ assets $(K>3)$ and $K+1$ states of nature.
} 
Cholesky triangle $\mathbf{L}$, the matrix $\mathbf{X}=\left(\mathbf{x}^{1}, \mathbf{x}^{2}, \mathbf{x}^{3}\right)$ of possible stock returns $x_{n}^{k}$ is calculated as:

$$
\mathbf{X}=\mathbf{Z L}+\mathbf{E}
$$

where:

$$
\mathbf{E}=\left(\begin{array}{ccc}
E^{1} & E^{2} & E^{3} \\
\vdots & \vdots & \vdots \\
E^{1} & E^{2} & E^{3}
\end{array}\right)_{(4 \times 3)}
$$

and $E^{k}$ is the expected return of stock $k$.

Finally, we obtain the martingale probabilities of the $n$ original states of nature $q_{1}, \ldots, q_{4}$ from the system of Equations (7):

$$
\begin{aligned}
& 1=e^{-r}\left[q_{1} e^{x_{1}^{1}}+q_{2} e^{x_{2}^{1}}+q_{3} e^{x_{3}^{1}}+q_{4} e^{x_{4}^{1}}\right] \\
& 1=e^{-r}\left[q_{1} e^{x_{1}^{2}}+q_{2} e^{x_{2}^{2}}+q_{3} e^{x_{3}^{2}}+q_{4} e^{x_{4}^{2}}\right] \\
& 1=e^{-r}\left[q_{1} e^{x_{1}^{3}}+q_{2} e^{x_{2}^{3}}+q_{3} e^{x_{3}^{3}}+q_{4} e^{x_{4}^{3}}\right] \\
& 1=q_{1}+q_{2}+q_{3}+q_{4} .
\end{aligned}
$$

Armed with these parameters, we construct the tree in a forward calculation using transition matrices to represent the connection between nodes at subsequent time steps. The branching over one time step under the first specification $\left(\mathbf{Z}^{(1)}\right)$ is illustrated in the left-hand graph of Figure 2. The second specification $\left(\mathbf{Z}^{(2)}\right)$ is shown in the right-hand graph. In both cases, one asset follows a binomial tree (left: $A$, right: $C$ ) while the other two follow trinomial trees. The notation $(i, j, k)$ in the graphs indicates which branches of stocks $A, B$, and $C$ are combined. It is important to note that while the movements of the stocks are shown side by side, they actually occur simultaneously. The whole graph spans only one time step of length $\Delta t$.

As can be seen in Figure 2, not all combinations of stock movements are allowed. For example, in the first specification, an upward movement of stock $A$ is only possible in combination with a middle movement of stocks $B$ and $C$. As there are four possible combinations and four market instruments (three stocks plus a risk-free asset), the market is complete in both specifications. The trees are also partly recombining. For example, the sequences $(1,1,1),(2,3,2)$ and $(2,3,2)$, $(1,1,1)$ result in the same node. The two specifications differ only in the way the multivariate geometric Brownian motion of stock prices is discretized; in both cases, the numerical option value converges to the unique arbitrage-free value as $\Delta t \rightarrow 0$.

We assume that all dividend payment dates and dividend yields are known. The stock prices at nodes following a dividend are adjusted accordingly (see Hull (2006), p. 401).

Next the barriers have to be taken into account, which is achieved by twice running the calculation backward. The main calculation assumes that none of the barriers have been broken so far. The auxiliary calculation is based on the opposite assumption, that at least one of the barriers has been triggered. They are combined as follows: in the main calculation, we replace the value of a node with that of the corresponding node in the auxiliary calculation if at least one stock 
Stock $A \quad$ Stock $B \quad$ Stock $C$

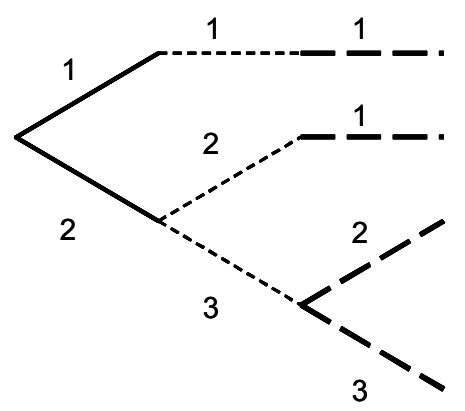

Stock $A \quad$ Stock $B \quad$ Stock $C$

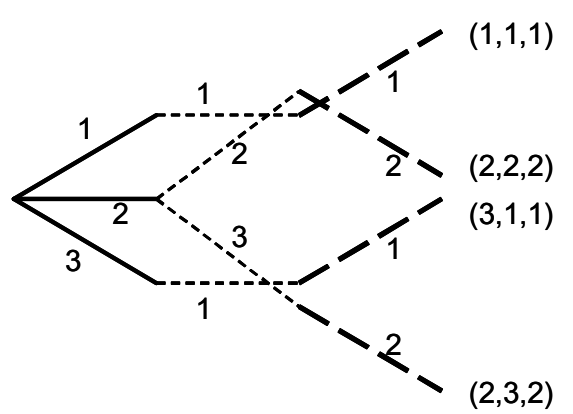

Figure 2: Tree specifications in a multivariate, complete market setting for one time step of length $\Delta t$

price falls short of the knock-in boundary. Finally, the main calculation at the root of the tree gives the fair value of the three-asset barrier option.

To ensure correct implementation of the algorithm, we confirmed its congruence with the Johnson (1987) analytical model (no barrier case), with the analytical values of single-barrier options, and with triple-barrier reverse convertible (TBRC) values derived from Monte Carlo simulation ${ }^{6}$.

\subsection{Convergence}

When using a tree method to value barrier options, one typically finds that the fair value obtained depends on the number of time steps considered. The estimate evolves in a "saw-tooth" pattern (Boyle and Lau (1994)) as the number of steps increases. Therefore, a large number of time steps is required to ensure accuracy. For several reasons, this problem is less important in our valuation. First, the variations are less pronounced if barrier levels are low compared to current stock prices as is the case for the TBRCs in our sample. Second, at a given time step, the number of nodes in our tree is far larger than it would be in a fully binomial model. Third, our trees are not centralized: unlike the Cox et al. (1979) binomial model, stock prices at $t$ do not reappear two steps later.

Table 1 lists some characteristics typical of TBRCs offered in Switzerland. The convergence pattern for a product with exactly these characteristics is shown in Figure 3. The model converges quickly, achieving a nearly constant value for tree refinements of 100 steps and above. We produced these graphs for a random sample of 50 TBRCs in our database, always finding the convergence just as smooth. In the empirical study, we compute values based on the first specification $\left(\mathbf{Z}^{(1)}\right)$ with 200 time steps.

\footnotetext{
6 We implemented the Monte Carlo simulation in $\mathrm{C}++$ and computed values for typical TBRC parameter sets. Over 10 million random samples and 5000 time steps, deviations from the tree-based numerical values were always below $0.2 \%$.
} 


\begin{tabular}{ll}
\hline Time to maturity & 1 year \\
Coupon & $11 \%$ p.a., semi-annual payment \\
Risk-free rate of return & $3 \%$ p.a. (continuously compounded) \\
Dividend Yield & $1 \%$ for all underlying stocks \\
Time of dividend payment stock A & After 3 months \\
Time of dividend payment stock B & After 6 months \\
Time of dividend payment stock C & After 9 months \\
Barrier levels & $75 \%$ for all underlying stocks \\
Volatilities (Stocks A,B,C) & $23 \%, 29 \%, 32 \%$ \\
Correlation coefficient A,B & 0.27 \\
Correlation coefficient A,C & 0.50 \\
Correlation coefficient B,C & 0.39 \\
\hline
\end{tabular}

Table 1: Typical characteristics of the TBRCs in our sample

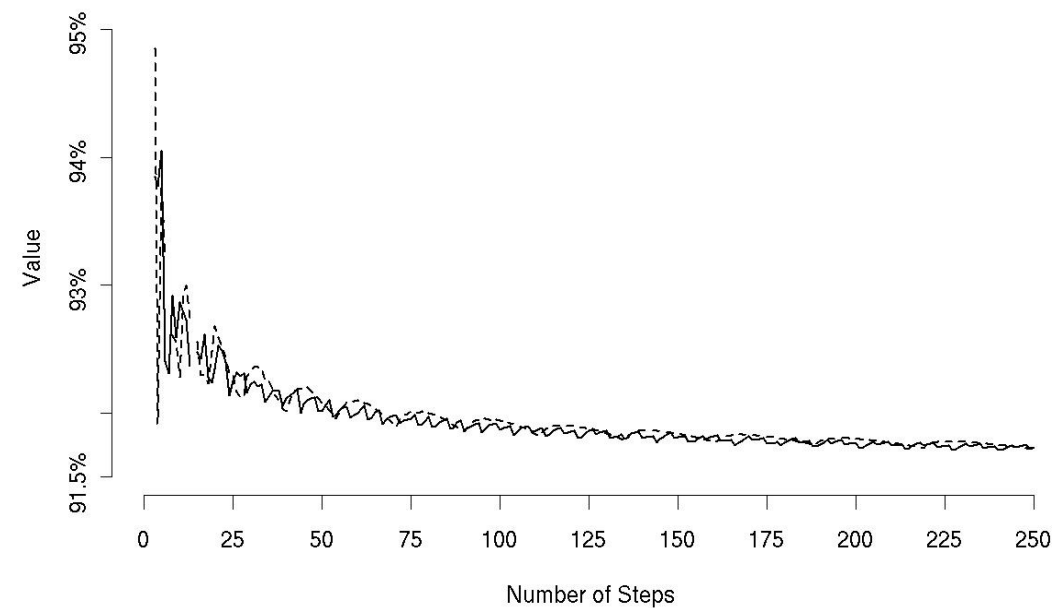

Figure 3: Numerical TBRC values for different tree refinements (example); unbroken line: first specification $\left(\mathbf{Z}^{(1)}\right)$; dashed line: second specification $\left(\mathbf{Z}^{(2)}\right)$ 


\subsection{Importance of stock price dynamics}

Our valuation model is based on standard assumptions analogous to the Black and Scholes (1973) model. However, as is apparent from the smile in option prices, jumps and stochastic volatility are important characteristics of asset price processes. Both increase the probability of hitting the barrier, which has a negative impact on the theoretical value of barrier reverse convertibles. For this reason, values derived from the Black-Scholes framework can be regarded as upper bounds on fair values. Thus, our measure of overpricing can be interpreted as the lowest estimate compatible with the data.

We use the at-the-money implied volatility of traded options as an estimate of the volatility of asset returns in the Black-Scholes framework. In this way, we take into account the at-the-money strike of the option embedded in the TBRCs, but ignore the fact that the option also includes a barrier.

As an alternative, we use the higher implied volatility at the barrier level and ignore the at-themoney strike. This estimate of overpricing will tend to be exaggerated, and plays the role of an upper bound on the level of overpricing. ${ }^{7}$

Another observation not considered in our valuation model is that correlations tend to be high in falling markets. This increase (also known as the "break-down") of correlations appears to enhance the fair value of the MBRC. The main reason why the level of correlation is positively related to the fair product value is that higher correlations reduce the probability of hitting one of the barriers. This is less relevant in crash situations, of course, where the barriers will tend to be broken anyway. We therefore suppose that the break-down of correlations during market crises does not have a strong impact on the fair value.

\section{Hypotheses}

In the empirical part of this study, we consider the direction and magnitude of deviations between TBRC issuing prices and their theoretical fair values. We present two hypotheses based on market frictions, followed by four based on behavioral arguments.

TBRCs are innovative products that investors cannot easily create on their own. Their high sales volume indicates that they are attractive to many investors. We expect the issuers to claim compensation for their structuring efforts, and presume that clients are willing to pay a premium for the package. This leads to our main hypothesis:

(H1) TBRCs are, on average, priced above their theoretical values.

Hedging is supposed to be less costly for the issuers in cases where the underlying assets are stocks with a generally high trading volume. In the Swiss market many TBRCs are based on the most liquid stocks, including a small number of Swiss blue chips. The competition among

\footnotetext{
7 We emphasize that this is not an upper bound in the strict sense. There may well be variances and stock return processes compatible with the observed smiles that produce even lower fair values. To our knowledge, results on strict upper and lower bounds of multivariate barrier options are not available in the literature.
} 
issuers is expected to be particularly strong whenever the issuing prices of products based on the same set of underlying assets can be directly compared. We therefore hypothesize:

(H2) The overpricing is less pronounced for TBRCs based on stocks which are often chosen as underlying assets.

Structured financial products are often regarded as flexible tools enabling investors to construct tailor-made risk-return profiles. According to this view, the issuing banks try to create innovative elements that are able to fill gaps in the financial markets. In a rational behavior environment, there is no reason to believe that premiums will be systematically related to product characteristics. However, the success of these products is difficult to explain under full rationality. Given the complexity associated with TBRCs, it is not obvious why investors should be interested in taking the risk. Thus, a reasonable alternative to rationality is the assumption that investors display behavioral biases. These biases are expressed in the following four hypotheses.

Since TBRC advertisements typically emphasize high coupons, we presume that investors put too much weight on the fixed coupon. The higher the coupon, the less sensitive investors are to the uncertainty of repayment. Thus, our third hypothesis is:

(H3) The overpricing is higher for products with high coupons.

If investors underestimate the downside risk of TBRCs, this bias should be stronger when volatilities are high and correlations are low. This hypothesis is related to Hypothesis (H3), because high volatilities and low correlations enable the issuers to offer higher coupons. As there is no simple linear relationship between coupons, volatilities and correlations, however, we include the hypotheses:

(H4) The overpricing is higher when the volatilities of the underlying asset returns are high.

(H5) The overpricing is higher when the correlations between the underlying asset returns are weak.

Technically, the coupon consists of a risk-free payment for the bond component. It represents compensation for the issuer's credit spread, and a premium for the option component (less the issuer's margin). The first element depends directly on the currency. Due to higher interest rates, using Euros instead of Swiss Francs significantly increases the "fair" coupon, making it visually more attractive. We presume that investors do not fully account for this interest rate difference, thus:

(H6) The overpricing is higher for products denominated in currencies with higher (nominal) interest rates.

\section{Data}

Our database consists of all TBRCs outstanding at the end of April 2007. We collected the product characteristics from their final termsheets. All products are designed such that the issuing price is equal to the nominal value (of 100). We only consider products with stocks as underlying assets, and require Eurex options on these stocks to be available. In addition, we 
exclude TBRCs with an initial time to maturity of more than 430 calendar days because trading activity is very low in such long-term Eurex options. Starting with 832 stock-based TBRCs, the time-to-maturity requirement reduces this number by 76 and the Eurex option condition by another 288. Thus, our final database consists of 468 TBRCs.

The five most important issuers are UBS, Clariden Leu, Julius Bär, Goldman Sachs and Credit Suisse (see Table 2). The "big five" stocks in the Swiss Market Index (Credit Suisse Group, Nestlé, Novartis, Roche Holding, UBS), plus ABB and Zurich Financial Services, are the most frequently used underlying assets in our final database.

Barriers range from $50 \%$ to $85 \%$ of the stock prices at issuance (fixing prices). There is a clear preference for round numbers or one percentage point less, for instance $69 \%$ and $70 \%$ (left-hand graph of Figure 4). Some issuers pay the whole coupon at maturity, while others split it into several parts. To make the payments comparable, we discount coupons to the issuance date. The discounted coupons range from $3.3 \%$ to $17 \%$ of nominal, with an average of $10.4 \%$ (right-hand graph of Figure 4).

We assume dividend yields and dividend payment dates to be the same as in 2006. Risk-free rates are defined as the 12-month interbank offered rates in the corresponding currency. Credit spreads at the valuation date are assumed to be equal to the premium of credit default swaps on senior debt of the issuer. If this information is not available from Thomson Financial Datastream or Bloomberg, we assume a constant credit spread of 25 basis points. This value appears to be a realistic estimate for the time period under study.

Based on Eurex settlement data, we calculate implied volatilities for all strike prices and maturities available. To account for the American style of Eurex stock options, we apply the binomial model to determine implied volatilities, i.e., we evaluate an option with different volatility input parameters until convergence to the settlement price is achieved. We then apply a two-step interpolation scheme to match the moneyness and maturity dates of TBRCs and Eurex options. In the first step, following Hafner and Wallmeier (2001), we estimate the smile function for each option maturity based on a cubic regression of implied volatilities on moneyness. In the second step, we linearly interpolate between the implied variances of the smile functions surrounding the maturity date of the TBRCs. We use the at-the-money implied volatility as an estimate of the volatility of log stock returns in the numerical valuation of TBRCs. Since market estimates of correlations are not available, we compute historical correlations of daily log returns over the last year. We check the robustness of our results with respect to this estimate.

Following Wilkens and Stoimenov (2007), our measure of overpricing $\Delta V_{i}$ is the relative difference between the issuing price $P_{i}^{M}$ of TBRC $i$ and the corresponding theoretical value $P_{i}^{T}$ :

$$
\Delta V_{i}=\frac{P_{i}^{M}-P_{i}^{T}}{P_{i}^{T}}=\frac{100-P_{i}^{T}}{P_{i}^{T}} .
$$

If $\Delta V_{i}<0$, the product is said to be underpriced. Overpricing (in the sense that $\Delta V_{i}>0$ ) does not imply that the issuing price is inappropriate, merely that a premium is demanded in excess of the theoretical value.

Another way to illustrate the magnitude of overpricing is to assume that it can be fully attributed to the barrier put option component of the product, and that the straight bond component is 
fairly priced. This gives us the modified measure:

$$
\Delta V_{i}^{*}=\frac{O_{i}^{M}-O_{i}^{T}}{O_{i}^{T}}
$$

where $O_{i}^{M}$ is the present value of coupons in excess of effective interest rates of straight bonds of the issuer (option premium paid), and $O_{i}^{T}$ is the theoretical value of the embedded multi-asset barrier put.

\begin{tabular}{llr}
\hline Issuer & Product name & Number of TBRCs \\
\hline UBS & Kick-In GOAL on Worst of & 95 \\
Clariden Leu & Multi Barrier Reverse Convertible & 76 \\
Julius Bär & Triple ICE Unit & 58 \\
Credit Suisse Group & Equity Yield Note & 45 \\
Bank Vontobel & Multi Defender Vonti & 45 \\
Zürcher Kantonalbank & Soft-Runner on Worst of & 37 \\
Goldman Sachs & Multi Barrier Reverse Convertible & 33 \\
Banque Cantonale Vaudoise & LEMAN DEFENSIF WORST OF & 22 \\
Bank Sarasin & SaraSail Rainbow mit Barriere & 20 \\
Citigroup & Barrier Reverse Convertible & 17 \\
Merrill Lynch & Callable Worst of Kick-in Reverse Convertible & 10 \\
Sal. Oppenheim & BARRIER-TRIPLE-REVERSE-CONVERTIBLE & 10 \\
\hline Total & & 468 \\
\hline
\end{tabular}

Table 2: Issuer, product name and number of TBRCs in the final database

\section{Empirical results}

\subsection{Magnitude of overpricing at issuance}

As can be seen from the left-hand graph in Figure 5, 98\% of all TBRCs (459 of 468) are overpriced $\left(\Delta V_{i}>0\right)$. The mean $\Delta V_{i}$ value of $3.4 \%$ is significantly positive, which strongly supports Hypothesis (H1). If we attribute the overpricing to the embedded put, we find a mean relative price difference $\left(\Delta V_{i}^{*}\right)$ of $-28.6 \%$ (right-hand graph of Figure 5). Descriptive statistics related to both histograms can be found in Table 3. Thus, the typical TBRC investment can be interpreted as buying a straight bond at its fair value while selling a knock-in put at $28.6 \%$ below its theoretical value. In the following discussion, however, we focus on $\Delta V_{i}$ rather than $\Delta V_{i}^{*}$ so that our results are directly comparable to previous studies.

We argued in Section 3.4 that those determinants which have not been considered in our model tend to decrease the fair value of a TBRC. To get an idea of the maximal overpricing compatible with the data, we also computed theoretical values within the Black-Scholes framework using implied volatilities at the barrier level instead of ATM implied volatilities. This results in a mean price deviation of $6.0 \%$ (see Table 3). Thus, realistic estimates of the average magnitude of overpricing range from $3.4 \%$ to $6.0 \%$, a level which is both statistically and economically significant. 

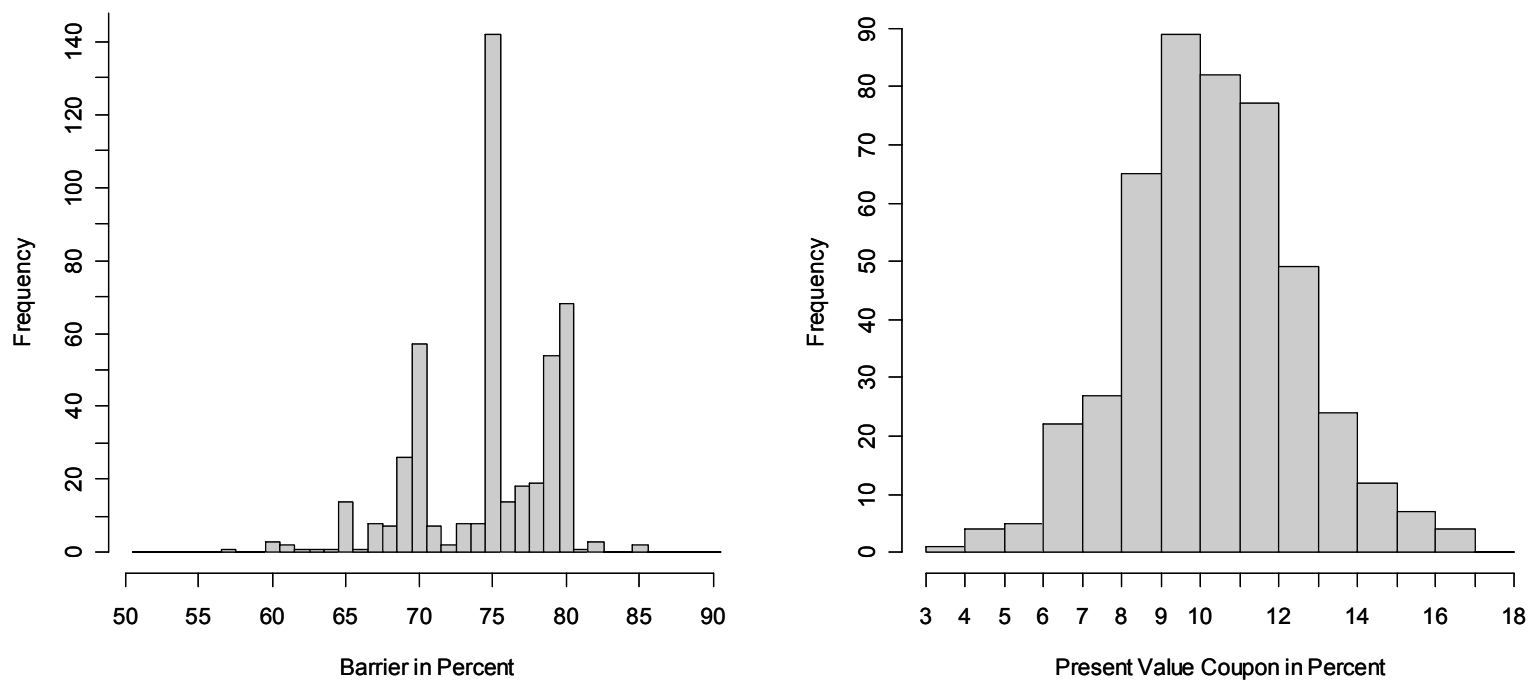

Figure 4: Frequency distributions of barrier levels and discounted coupons

\begin{tabular}{lrrrrrrr}
\hline & Minimum & 1st Qu. & Median & Mean & 3rd Qu. & Maximum & Std.Dev. \\
\hline$\Delta V_{i}$ ATM & -0.0254 & 0.0235 & 0.0330 & 0.0341 & 0.0438 & 0.1141 & 0.0166 \\
$\Delta V_{i}^{*}$ ATM & -0.7600 & -0.3452 & -0.2903 & -0.2855 & -0.2244 & 0.1520 & 0.1084 \\
$\Delta V_{i}$ OTM & 0.0150 & 0.0501 & 0.0593 & 0.0602 & 0.0685 & 0.1285 & 0.0145 \\
\hline
\end{tabular}

Table 3: Descriptive statistics of the relative price differences. ATM: based on at-the-money implied volatilities. OTM: based on implied volatilities for strikes equal to barrier levels 

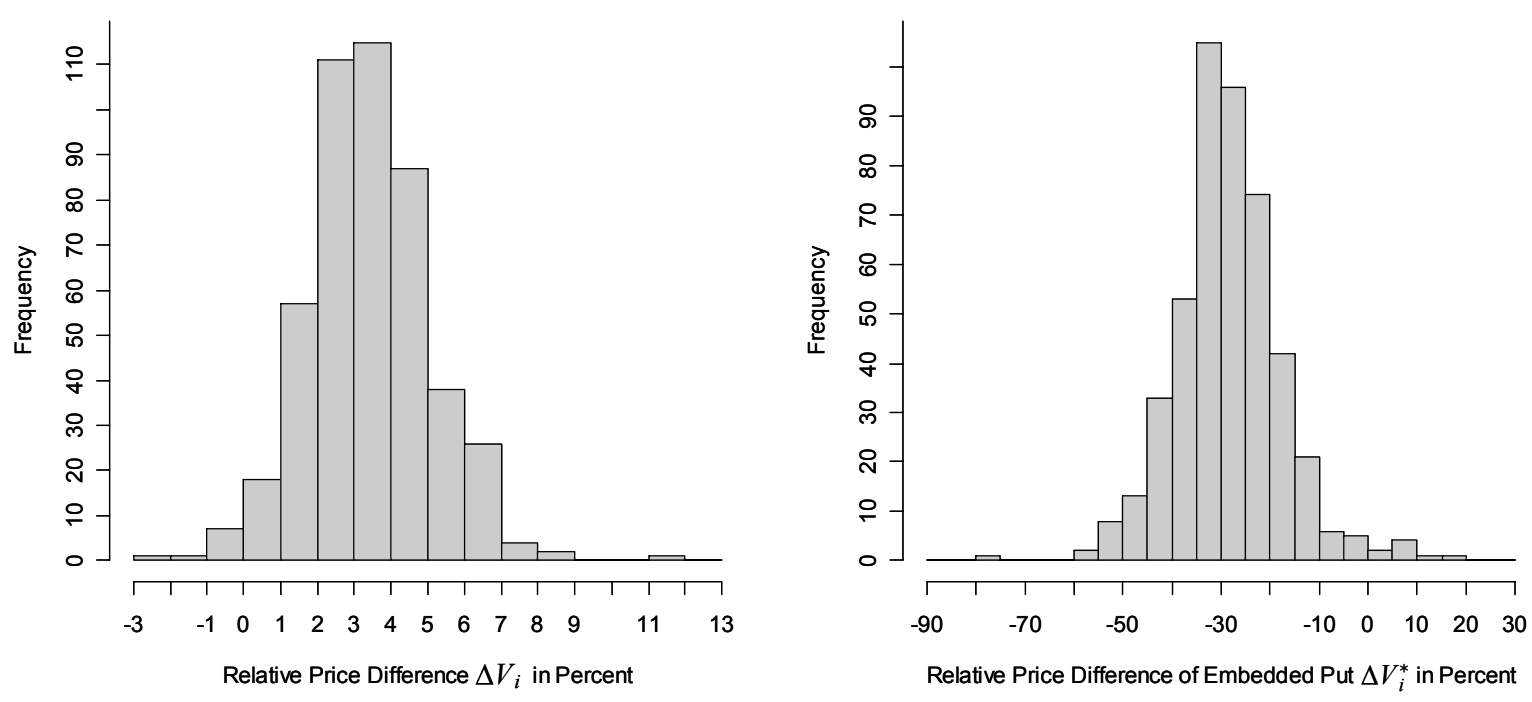

Figure 5: Frequency distributions of the relative price differences $\Delta V_{i}$ and $\Delta V_{i}^{*}$

\subsection{Determinants of overpricing}

To analyze the impact of market frictions and behavioral biases on the premium of TBRCs, we estimate the following multiple regression model:

$$
\Delta V_{i}=\beta_{0}+\beta_{1} C_{i}+\beta_{2} V O L_{i}+\beta_{3} C O R R_{i}+\beta_{4} B I G 7_{i}+\beta_{5} r_{i}+e_{i}
$$

where $\beta$ are regression coefficients. The explanatory variables are defined below:

$C_{i} \quad: \quad$ Present value of coupon payments for TBRC $i$,

$V O L_{i} \quad$ : Mean at-the-money implied volatility of the three underlying stocks,

$C O R R_{i}$ : Mean of the three pairwise correlations between daily returns of the underlying stocks over the last year,

$B I G 7_{i} \quad$ : Dummy variable which is 1 if at least one of the underlying assets belongs to the seven most frequently chosen stocks ${ }^{8}$, and 0 otherwise,

$r_{i} \quad: \quad$ Risk-free rate of return in the currency of TBRC $i$ on the fixing date.

Due to measurement error in $C O R R$, this variable may be endogenous in model (8). If our historical estimates of pairwise correlations overstate the "true" correlations, our theoretical fair value will be too high and the pricing difference $\Delta V$ will be too low. This implies that $C O R R$ might be correlated with the error component $e$. The same argument holds for $V O L$. Although our volatility estimates are derived from the observed market prices of options, matching with respect to moneyness and time to maturity induces some measurement error. In addition, implied volatility itself is merely an estimate of the unobservable return volatility. If volatility is overestimated, we obtain low theoretical fair values and high pricing differences. Again, this

8 Credit Suisse Group, Nestlé, Novartis, Roche Holding, UBS, ABB, and Zurich Financial Services. 
results in a correlation between $V O L$ and $e$. The Hausman (1978) test for endogeneity confirms that $C O R R$ and $V O L$ have to be regarded as endogenous variables.

To account for endogeneity, we apply the method of instrumental variables. We use the average historical volatility of daily stock returns over 252 trading days before issuance of the TBRC, $z_{v}$, as an instrumental variable for $V O L$, and the average historical correlation two years before issuance (trading days -504 to -253 ), $z_{c}$, as an instrumental variable for CORR. In simple linear regressions of $V O L$ on $z_{v}$ and $C O R R$ on $z_{c}$, the slopes are highly significant (p-values $<0.0001) ; z_{v}$ and $z_{c}$ explain $62 \%$ and $39 \%$ of the variation of $V O L$ and CORR respectively.

The results of the instrumental variable estimation are given in Table $4 .^{9}$ The $t$-values are based on heteroskedasticity-robust standard errors. The highest variance inflation factor is below 4 , which indicates that multicollinearity is weak.

\begin{tabular}{lrrrr}
\hline & Estimate & Std. Error & t-value & p-value \\
\hline$C$ & $0.1350^{* *}$ & 0.0508 & 2.6558 & 0.0082 \\
VOL & 0.0480 & 0.0615 & 0.7814 & 0.4350 \\
CORR & -0.0032 & 0.0108 & -0.2986 & 0.7654 \\
BIG7 & $-0.0062^{*}$ & 0.0026 & -2.3921 & 0.0172 \\
$r$ & -0.0034 & 0.0019 & -1.8018 & 0.0722 \\
\hline
\end{tabular}

Table 4: Results of instrumental variables estimation. ${ }^{*}(* *)$ : significant on the 5 percent (1 percent) level in a two-sided $t$-test.

In accordance with Hypothesis (H2), the estimated coefficient of $B I G 7$ is negative at the $5 \%$ confidence level. If at least one of the underlying assets is among the seven most frequently used stocks, the premium decreases by about 0.6 percentage points (e.g., from $3 \%$ to $2.4 \%$ ). From Hypotheses (H1) and (H2) we conclude that market frictions have an important impact on the pricing of TBRCs in the primary market.

The significantly positive ( $1 \%$ confidence level) estimate of $\beta_{1}$ indicates that overpricing is positively related to the present value of coupon payments, as suggested by Hypothesis (H3). This finding is consistent with the notion that investors strongly focus on the magnitude of the coupon and underweight the risks involved. A share of $13.5 \%$ of a 1 percentage point increase in the coupon is retained by the issuer, corresponding to 13.5 cents of a 1 dollar increase in coupon payments. This additional premium is clearly relevant in statistical as well as economic terms. In all, the regressors explain $7.9 \%$ of the variation of pricing differences $\Delta V$. We do not find support for the other three behavioral biases, Hypotheses (H4) to (H6). The coupon appears to play the central role for investor behavior.

Our results are robust with respect to the following modifications. In accordance with Hypothesis (H4), variable BIG7 could be defined as taking on the value 1 only if all three assets belong to the group of seven most frequently used stocks. This does not change the significance of coefficients $\beta_{1}$ and $\beta_{4}$. It might also be the case that premiums decreased over time as the

\footnotetext{
9 Since there is one instrumental variable for each endogenous explanatory variable, the instrumental variable
} estimator is identical to the two-stage least squares estimator. 
TBRC developed into an important structured product. However, such a decline would be difficult to detect in our sample since the fixing dates vary by only one year (May 2006 to April 2007). As expected, including a fixing time variable in Equation (8) does not show a significant influence. We estimated Equation (8) with issuer-specific dummy variables in order to account for differences among the banks. Again, results for coefficients $\beta_{1}$ to $\beta_{4}$ remain the same. Finally, we repeated the analyses using correlations from the last three years instead of the last year as input parameters. The average overpricing increases from $3.4 \%$ to $3.8 \%$, but results on the determinants of overpricing are confirmed.

\section{Conclusion}

Our main contributions are a numerical evaluation of triple barrier reverse convertibles and an empirical study of their pricing in the primary market. Compared to theoretical values, we obtain an average overpricing of at least $3.4 \%$. This is much higher than the average overpricing of $1.91 \%$ for simple reverse convertibles found in the Swiss market by Burth et al. (2001). Thus, greater complexity appears to entail higher premia, which is in line with expectations since complex products are more costly to hedge.

The average premium is rather low compared to results of previous studies in other countries, which is consistent with the advanced stage of development of structured products in the Swiss market. However, expressing the overpricing as a percentage of face value, as is common practice in the literature, could be misleading. One element of a TBRC is a straight bond, for which the premium at issuance is almost negligible. If we attribute the premium only to the short option component of TBRCs, an overpricing of $3.4 \%$ means that the option premium received by the buyer of a TBRC is on average $28.6 \%$ below its Black-Scholes value. This discount appears all the more important because out-of-the-money puts are typically traded at a premium compared to the Black-Scholes model. This downside raises the important question what characteristics make TBRCs so attractive to investors. Our analysis of the determinants of overpricing gives some insight into this problem, although a conclusive answer has to be left to future research.

First of all, overpricing is slightly reduced when the most popular stocks are chosen as underlying assets. Second, overpricing is positively related to the coupon, which confirms the presumption that investors tend to overestimate the importance of a sure coupon payment and underestimate the risk involved. The success of MBRCs in Switzerland is thus consistent with a behavioral explanation.

Given that interest rates in Swiss francs have been extremely low over the past few years, investors have generally been attracted to products with high coupons. Given the low level of stock return volatility, however, visually attractive coupons could only be offered by extending the asset base of reverse convertibles to several stocks. In this view, barrier protection might serve the purpose of enhancing the tendency of investors to underestimate the remaining downside risk. It seems worthwhile to further investigate the role of investor perception in experimental and empirical research.

We conclude by pointing out two limitations of our work. First, our theoretical valuation is based on standard simplifying assumptions. Though these have allowed us to estimate the range 
of overpricing compatible with the data, the natural next step would be to attempt to value MBRCs in a framework including jumps and stochastic volatility. Second, our hypotheses on the determinants of pricing differences did not come from an equilibrium theory of optimal issuer and investor behavior. For instance, if premiums are higher for MBRCs with high coupons, we would expect high-coupon products to prevail in the market. In general, the motives for issuing certain types of products and the choice of product characteristics such as underlying assets merit closer investigation.

\section{References}

Benet, B., Giannetti, A. and Pissaris, S. (2006). Gains from structured product markets: The case of reverse-exchangeable securities (RES), Journal of Banking and Finance 30(1): 111132.

Black, F. and Scholes, M. (1973). The pricing of options and corporate liabilities, Journal of Political Economy 81: 637-654.

Boyle, P., Evnine, J. and Gibbs, S. (1989). Numerical evaluation of multivariate contingent claims, Review of Financial Studies 2(2): 241-250.

Boyle, P. and Lau, S. (1994). Bumping up against the barrier with the binomial method, Journal of Derivatives 1: 6-14.

Branger, N. and Breuer, B. (2008). The Optimal Demand for Retail Derivatives, Working Paper University of Münster.

Breuer, W. and Perst, A. (2007). Retail banking and behavioral financial engineering: The case of structured products, Journal of Banking and Finance 31(3): 827-844.

Burth, S., Kraus, T. and Wohlwend, H. (2001). The pricing of structured products in the Swiss market, Journal of Derivatives 8(Winter): 30-40.

Chen, R.-R., Chung, S.-L. and Yang, T. (2002). Option pricing in a multi-asset, complete market economy, Journal of Financial and Quantitative Analysis 37(4): 649-666.

Cox, J., Ross, S. and Rubinstein, M. (1979). Option pricing: A simplified approach, Journal of Financial Economics 7: 229-263.

Cox, J. and Rubinstein, M. (1985). Options Markets, Englewood Cliffs, New Jersey.

Erner, C., Klos, A. and Langer, T. (2008). Can Prospect Theory Be Used To Predict Investor's Willingness To Pay?, Working Paper University of Münster.

Grünbichler, A. and Wohlwend, H. (2005). The valuation of structured products: Empirical findings for the Swiss market, Financial Markets and Portfolio Management 19(4): 361380 .

Hafner, R. and Wallmeier, M. (2001). The dynamics of dax implied volatilities, International Quarterly Journal of Finance 1: 1-27.

Hausman, J. (1978). Specification tests in econometrics, Econometrica 46: 1251-1271. 
Hens, T. and Rieger, M. (2008). The Dark Side of the Moon: Structured Products from the Customer's Perspective, Working Paper University of Zurich.

Hernandez, R., Lee, W. and Liu, P. (2007). An Economic Analysis of Reverse Exchangeable Securities - An Option-Pricing Approach, Working Paper University of Arkansas.

Hull, J. (2006). Options, Futures, and Other Derivatives, 6th edn, Prentice Hall.

Johnson, H. (1987). Options on the maximum or the minimum of several assets, Journal of Financial and Quantitative Analysis 22(3): 277-283.

Kahneman, D. and Tversky, A. (1979). Prospect theory: An analysis of decision under risk, Econometrica 47(2): 263-291.

Kahneman, D. and Tversky, A. (1992). Advances in prospect theory: Cumulative representation of uncertainty, Journal of Risk and Uncertainty 5(4): 297-323.

Musiela, M. and Rutkowski, M. (2005). Martingale Methods in Financial Modelling, 2nd edn, Springer.

Rathgeber, A. (2005). Mehrere Preisprozesse und Ausübungsbedingungen bei der Bewertung von Optionen, Books on Demand (Norderstedt).

Rendleman, R. and Bartter, B. (1978). Two-state option pricing, Journal of Finance 34: 10921110.

Schenk, C. and Wasserfallen, W. (1996). Portfolio insurance for the small investor in Switzerland, Journal of Derivatives 3(Spring): 37-43.

Shefrin, H. and Statman, M. (1993). Behavioral aspects of the design and marketing of financial products, Financial Management 22(Summer): 123-134.

Stoimenov and Wilkens (2005). Are structured products "fairly" priced? an analysis of the German market for equity-linked instruments, Journal of Banking and Finance 29(12): 29712993.

Stulz, R. (1982). Options on the minimum or the maximum of two risky assets, Journal of Financial Economics 11(2): 161-185.

Szymanowska, M., Horst, J. and Veld, C. (2007). Reverse Convertible Bonds Analyzed, Working Paper University of Rotterdam.

Thaler, R. (1985). Mental accounting and consumer choice, Marketing Science 4(3): 199-214.

Wilkens, S., Erner, C. and Röder, K. (2003). The pricing of structured products in Germany, Journal of Derivatives 10(Fall): 55-68.

Wilkens, S. and Stoimenov, P. (2007). The pricing of leverage products: An empirical investigation of the German market for 'long' and 'short' stock index certificates, Journal of Banking and Finance 31: 735-750. 